\title{
On the Criterion of Proximity to the True Value: Information Approach
}

\author{
Ilya Feldman \\ Moscow State University of Geodesy and Cartography, Moscow, Russia
}

Email address:

i.feldman@yandex.ru

To cite this article:

Ilya Feldman. On the Criterion of Proximity to the True Value: Information Approach. American Journal of Remote Sensing. Vol. 7, No. 1, 2019, pp. 1-4. doi: 10.11648/j.ajrs.20190701.11

Received: March 25, 2019; Accepted: May 28, 2019; Published: July 9, 2019

\begin{abstract}
What is the criterion of proximity to the true value of the measured value: absolute or relative error? The least squares method traditionally operates with absolute values of corrections to measured values, and the equalization is carried out under the condition of the minimum of the sum of squares of absolute corrections. However, as shown in the article, the informational approach leads to the conclusion that the measure of proximity to the true value is a relative measurement error. Therefore, it is advisable to carry out an equalization under the condition of a minimum of the sum of squares of not absolute, but relative corrections. This is equivalent to equalization, in which the weight of the correction depends on the size of the object being measured: the larger the object being measured, the smaller the weight of the corresponding amendment, and its value can be increased during equalization. In this case, the described approach leads to a kind of "method of least relative squares" (MLRS). Another interesting consequence of the information approach is that the relative measurement error modulus has the meaning of the probability of a measurement result deviating from the true value. The article presents the required information approach formulas for the weights of the amendments when using the MLRS. In particular, it is shown that the angular discrepancy distribution in a triangle depends on the lengths of the sides.
\end{abstract}

Keywords: The Criterion of Proximity, The True Value, Amount of Information, The Hartley-Shannon Formula, The Least Squares Method, The Weighting Factors to Amendments, The Distribution of Angular Discrepancy

\section{Introduction}

Consider the simplest example. If we know that the side length of 200 meters is measured with an error of $10 \mathrm{~cm}$, and the side length of 1000 meters-with an error of $30 \mathrm{~cm}$, what measurement is more accurate? Can answer: it depends on the choice of criteria. If you select absolute error as the criterion, the more accurate measurement is the first, and if relative error is the second. But which of these criteria can serve as a measure of proximity to the true value?

In the procedures of adjustment and evaluation of the accuracy of geodetic measurements relative error is rarely used. For example, in the voluminous textbook by A. S. Chebotaryov (А.С.Чеботарев) of the relative error is mentioned only twice in the introduction [1], p. 9, 10, and very briefly in the section "Absolute and relative measurement errors" [1], p. 71. The author admits that the relative error is an important criterion in assessing the accuracy of the measurements, but often does not have much practical sense and value.

The theory of equalization of geodetic measurements using the least squares method in all their sections and problems uses only absolute values of errors and corrections. We are convinced of it on examples of classical works of A. Legendre [2], C. F. Gauss [3-4], W. Jordan [5-6], F. Helmert [7], and also works of П.И.Шилов [8], Н.И.Идельсон [9] and others.

This article attempts to find an answer to the question about the criterion of proximity to the true value, using the information approach.

\section{The Criterion of Proximity to the True Value}

Let the true value of the measured value be $A$, and the result of the measurement is $a$, that is, the true error $d=A-$ $a$. 
In terms of information theory the measurement process is limiting the diversity of our knowledge about the object [10] p. 171,181 . At the initial moment we know nothing about the object. If the size of the object is $x$, then the variety, i.e. the number of possible measurement results, is characterized by the value $x / \varepsilon$, where $\varepsilon$ is some accepted quantization level (required measurement accuracy). The average value of diversity to the measurements is.

$$
R_{1}=\int_{0}^{S} \frac{x}{\varepsilon} p(x) d x=\frac{1}{\varepsilon} \int_{0}^{S} x p(x) d x
$$

where $p(x)$ is the probability density of $x, S$ is a value that exceeds $A$, such that the probability $P(x>S)=0$. The integral $\int_{0}^{S} x p(x) d x$ is the mathematic expectation of the size of the object, which is equal to $A$. Therefore $R_{1}=\frac{A}{\varepsilon}$.

After familiarizing with the object and performing measurements, the diversity will be reduced to the value $R_{2}=\frac{|d|}{\varepsilon}$ where $|d|$ is the true error module $d$.

The total amount of information obtained, equal to the difference between the entropies of the initial and after measurement, is determined by the value [11] p. 10, 382 .

$$
I=\log R_{1}-\log R_{2}=\log \frac{A}{\varepsilon}-\log \frac{|d|}{\varepsilon}=\log \frac{A}{|d|}=-\log \frac{|d|}{A}
$$

Comparing the expression (2) with the Hartley-Shannon formula $I=-\log p$ [11] p.34, [12] p. 78, we note that the relative measurement error makes sense of the probability $p$, characterizing the deviation of the measurement result from the true value. This result in itself is quite unexpected and very interesting.

Since the amount of information in (2) is determined not by an absolute but by a relative measurement error, the information approach leads to the conclusion that the criterion of proximity to the true value is the relative measurement error. And, thus, the answer to the question posed at the very beginning of the article: the measurement of the side with a length of $1000 \mathrm{~m}$ is more accurate, although the absolute error of this measurement is much greater than the absolute error of the measurement of the 200-meter side.

But in this case, the equalization under the condition $\sum v^{2} \rightarrow \min$, where the amendments $v$ are absolute values, it is necessary, from the point of view of the information approach, to recognize not quite correct. If it is important to reduce the relative errors of the measured values, the least squares adjustment criterion should have a different form.

The estimate of the true relative error $\frac{|d|}{A}$ after the equalization is the value $\frac{|v|}{a+v}$ where $v$ is the correction to the measurement result of $a$ from the adjustment. Because of the smallness of $v$ in comparison with $a$ as the estimation of the true relative error can be taken the value $\frac{|v|}{a}$. Therefore, it is reasonable to carry out the equalization under the condition of the minimum sum of squares of these quantities, that is, under the condition

$$
F=\sum_{i} \frac{v_{i}^{2}}{a_{i}^{2}} \rightarrow \min
$$

This type of criterion means that instead of absolute corrections $v_{\mathrm{i}}$, dimensionless relative values $v_{\mathrm{i}} / a_{\mathrm{i}}$ are used, where $a_{\mathrm{i}}$ is the result of measurement of object $i$. The trivial case of equality of all objects $a_{i}=a=$ const leads to the usual criterion $\sum v^{2} \rightarrow \min$.

Since the measured objects $a_{\mathrm{i}}$ have different sizes, in the function $F$ the same values of the summands have different weights. Therefore, it is necessary to use a weighted criterion

$$
F=\sum_{i} \frac{v_{i}^{2}}{a_{i}^{2}} a_{i}=\sum_{i} \frac{v_{i}^{2}}{a_{i}} \rightarrow \min
$$

The square root of the value $F$ determine the rms value of the relative error of all measured values after the equalization.

Expression (4) differ from the criterion $\sum v^{2} \rightarrow$ min in the presence of multipliers $\frac{1}{a}$, playing the role of weights.

The smaller the measured value, i.e. the result of $a$, the greater the weight of the corresponding amendment $v$, and this amendment will become smaller as a result of the equalization (and Vice versa).

Thus, the described approach leads to a peculiar "method of least relative squares" (MLRS).

It is clear that criterion (4) is directly applicable to linear measurements. In the case of angular measurements, the approach is somewhat different. The angular amendment $v$ to the measured direction on the side of the length $S$ will cause a linear deviation of the opposite end of the side.

$$
\Delta=\frac{v S}{\rho}
$$

Here $\rho$ is the radian in units of the angular amendment $v$.

This deviation, in turn, will lead to a relative measurement error of a line whose average length on the object is $S_{c p}$, equal.

$$
\frac{|\Delta|}{S_{\mathrm{cp}}}=\frac{|v| S}{\rho S_{\mathrm{cp}}}
$$

Summarizing the above, we conclude that the MLRS leads 
to the criterion of equalization.

$$
F=\sum_{i} k_{i} v_{i}^{2} \rightarrow \min
$$

where the weight coefficients for corrections to linear measurements are as follows.

$$
k_{i}=\frac{1}{a_{i}}
$$

a for corrections to angular measurements.

$$
k_{i}=\frac{S_{i}^{2}}{\rho^{2} S_{\mathrm{cp}}{ }^{2}}
$$

If the objects of linear measurements differ little in size, i.e. when all $S_{i} \approx S_{\text {cp }}$, then in (8) the weights of all angular corrections become the same, equal to $1 / \rho^{2}$.

In the case of unequal measurements criterion (6) takes the form.

$$
F=\sum_{i} P_{i} k_{i} v_{i}^{2} \rightarrow \min
$$

Here $P_{\mathrm{i}}$ is the weight describing the accuracy of measurement of objects $i[12$, p. 88].

\section{The Angular Closure Distribution in the Triangle Required by MLRS}

It follows from expressions (5) and (8) that the weight of the angular amendment in the measured direction is proportional to the square of the length $S$ of the corresponding side.

For example, if the lengths of the sides of the triangle $S_{1}$, $S_{2}, S_{3}$ differ significantly, then this should be taken into account when distributing the angle closure. Simple calculations related to finding the conditional extremum of the Lagrange function.

$$
L=\sum_{i} S_{i}^{2} v_{i}^{2}+\lambda\left(\sum_{i} v_{i}+f\right) \rightarrow \min
$$

lead to such expressions for amendments to the measured directions in a triangle.

$$
v i= \pm \frac{f}{2 C S_{\mathrm{i}}^{2}}
$$

where $i$ is the number of the triangle side; $f$ is the angle closure (with its sign);

$$
C=\frac{1}{S_{1}^{2}}+\frac{1}{S_{2}^{2}}+\frac{1}{S_{3}^{2}}
$$

the plus sign is taken for the left direction of corner, and the minus sign is taken for the right. At equality of the parties.

$$
v i= \pm \frac{f}{6}
$$

\section{Summary}

The information approach leads to the conclusion that the criterion of proximity to the true value is a relative error. Therefore, it is more reasonable to equalize the results of measurements under the condition of minimum sum of squares of relative rather than absolute corrections. Along the way, it turned out an interesting fact: it turns out that the relative error of measurement makes sense of the probability characterizing the deviation of the measurement result from the true value.

The applied methodology of equalization of geodetic measurements uses the minimization of absolute corrections, which is in contradiction with the information approach.

In article expressions are received (7), (8), (9) for the criterion of equalization under the condition of minimum sum of squares of relative corrections. Thus, the information approach leads to a kind of «method of least relative squares» (MLRS).

This approach requires, in particular, that the lengths of the sides be taken into account when finding corrections to the results of angular measurements. As an example, the formula (10) for the distribution of the angle closure in a triangle is derived.

\section{References}

[1] Чеботарев А. С. Способ наименьших квадратов с основами теории вероятностей. (Chebotaryov A. S. Least squares method with the basics of probability theory). - M: Геодезиздат, 1958.

[2] Legendre A. Nouvelles methodes pour la determination des orbites des kometes. (Legendre A. New methods for the determination of the orbits of kometes). - Paris, 1806.

[3] Gauss C. F. Methode des moindres carres. - Traduits par J. Bertrand. (Gauss C. F. Method of the least squares. Translated by J. Bertrand). - Paris, 1855.

[4] Гаусс К. Ф. Избранные геодезические сочинения, т. 1. Способ наименьших квадратов. - Перевод с немецкого. Под редакцией Г. В.Багратуни. (Gauss K. F. Selected geodesic works, vol. 1. Method of least squares. - Translated from German. Edited by G. V. Bagratuni). - М: Геодезиздат, 1957.

[5] Jordan W. Handbuch der Vermessungskunde. (Jordan W. Handbook of Surveying). - Stuttgart, 1920.

[6] Иордан В. Руководство по геодезии. - Перевод с немецкого. (Jordan W. Surveying Guide. - Translation from German). - Редбюро ГУГК, 1939.

[7] Helmert F. R.. Ausgleichungsrechnung nach der Methode der Kleinsten Quadrate. (Helmert F. R.. Equalization calculation according to the method of least squares). - Leipzig, 1872.

[8] Шилов П. И. Способ наименьших квадратов. (Shilov P. I. Least squares method). - М: Геодезиздат, 1941. 
[9] Идельсон Н. И. Способ наименьших квадратов и теория математической обработки наблюдений. (Idelson N. I. Least squares method and theory of mathematical processing of observations). - М: Геодезиздат, 1947.

[10] Ashby W. Ross. An Introduction to Cybernetics. - London, Chapman \& Hall ltd, 1956.
[11] Goldman St., Information Theory. - London, Constable and Company, 1953.

[12] Маркузе Ю. И., Бойко Е. Г., Голубев В. В. Геодезия. Вычисление и уравнивание геодезических сетей. (Markuze Yu. I., Boyko E. G., Golubev V. V. Geodesy. Calculation and equalization of geodetic networks). - М.: Картгеоцентр Геодезиздат, 1994. 